\title{
ESTIMATION OF COTTON AND MAIZE CROP AREA IN PERAMBALUR DISTRICT OF TAMIL NADU USING MULTI-DATE SENTINEL-1A SAR DATA
}

\author{
Ashmitha Nihar M. ${ }^{1}$, Mohammed Ahamed J. ${ }^{2}$ *, Pazhanivelan S. ${ }^{3}$, Kumaraperumal R. ${ }^{3}$ and Ganesha Raj K. ${ }^{2}$ \\ ${ }^{1}$ Indian Institute of Remote Sensing, ISRO, Dehradun 248001 - ashmitha.sab@gmail.com \\ ${ }^{2}$ RRSC-South, NRSC, ISRO, Dept. of Space, Bengaluru 560037 - (ganeshraj, mohammedahamed_j)@nrsc.gov.in \\ ${ }^{3}$ Department of Remote Sensing \& GIS, University of Agricultural Sciences, Coimbatore, Tamil Nadu - pazhanivelans@gmail.com
}

Commission III, WG III/10

KEY WORDS: Sentinel-1A, Cotton, Maize, Spectral Angle Mapper, Decision Tree Classifier

\begin{abstract}
:
Crop classification is a key issue for agricultural monitoring using remote sensing techniques. Synthetic Aperture Radar (SAR) data has an advantage in crop classification because of its all-weather imaging capabilities. The objective of this study was to investigate the capability of SAR data for estimation of cotton and maize area in Perambalur district of Tamil Nadu. The multi-temporal Sentinel-1 SAR data was acquired from $02^{\text {nd }}$ September, 2017 to $24^{\text {th }}$ January, 2018. Both the Vertical - Vertical (VV) and VerticalHorizontal $(\mathrm{VH})$ polarized data was used. Ground truth data collection was performed for cotton and maize during the vegetative, flowering and harvesting stages. Sixty per cent of the ground truth data were used for training and remaining forty per cent were utilized for validation. The temporal backscattering coefficient $(\sigma 0)$ for cotton and maize were extracted using the training datasets.. The mean backscattering values for cotton crop during the entire cropping period had a range from $-11.729 \mathrm{~dB}$ to $-8.827 \mathrm{~dB}$ and from $-19.167 \mathrm{~dB}$ to $-14.186 \mathrm{~dB}$ for $\mathrm{VV}$ and $\mathrm{VH}$ polarization respectively. For maize crop it ranged from $-11.248 \mathrm{~dB}$ to $-8.878 \mathrm{~dB}$ and from $-19.043 \mathrm{~dB}$ to $-14.753 \mathrm{~dB}$ for VV and VH polarized data respectively. The Spectral Angle Mapper (SAM) and Decision Tree classifier (DT) methods were adopted for cotton and maize area estimation. SAM classified 73259 and 51489 hectares (ha) as cotton and maize respectively in VV polarization. DT classified the area of 61501 and 64530 ha for cotton and maize respectively in VH polarization. The accuracy measures, such as overall accuracy, producer's accuracy and user's accuracy and kappa coefficient were estimated. SAM classifier exhibits the overall accuracy of $73.3 \%$ for VV Decision tree classifier reported the overall accuracy of $75.0 \%$ for VH. It is evident from the present study, that the multi-temporal Sentinel-1 SAR sensor can be well used for the discrimination of cotton and maize crops because of its high temporal resolution which captures the complete phenology of the crops during the cropping period.
\end{abstract}

\section{INTRODUCTION}

The importance of agriculture for the Indian society can hardly be over-emphasized, as its role in economy, employment, food security, national self-reliance and general wellbeing, does not need reiteration. The need for timely and reliable information on crop area and production for tactical and strategic decision making by all stakeholders in agriculture, such as producers, processors, resource managers, marketing, finance and the government is well known. With the global shift in the market economies, reliable agricultural information has gained more importance than ever before.

A crop information system is one way that remote sensing can provide valuable information to decision-makers. Remote sensing is presently the only technology that can provide timely and accurate crop inventory information. When the advantages of various remote sensing platforms are compared and it is clear that repetitive coverage is unique to the orbiting spacecraft.

In past decades, crop identification and crop area estimation was fairly successful using space borne sensors operated in the visible and near-infrared regions of the spectrum (Brisco et al., 1998, Dadhwal et al., 2000 and Fisette et al., 2005). However the dependence of optical sensors on the sun's energy limits the image acquisition during cloudy or rainy conditions. As a result, less cloud free optical images are available during inseason for monitoring crops (Schuster et al., 2011). Thus, there is a need of remote sensing system which can be operated in allweather conditions. Radar has a great potential to provide information in such a manner. Previous research has demonstrated the large potential of SAR images for crop acreage estimation and crop monitoring (Shang et al., 2009, Moran et al., 2011, and McNairn et al., 2013). In addition, with the current state-of-the-art of interpretation methods for SAR imagery, the accuracies of crop classification are not always as high as required for better decision making. To be able to increase the accuracies of crop identification and area estimation, we need to (a) have a better understanding of the crop and the underlying soil characteristics that influence the radar backscatter throughout the growing season, (b) identify a suitable methodologies to extract crop information from SAR imagery and (c) evaluate the multi temporal SAR data for crop identification.

With this background knowledge the present investigation was carried out to evaluate the multi-temporal SAR imagery for identification and estimation of cotton and maize crop area in Perambalur district of Tamil Nadu.

\footnotetext{
* Corresponding author
} 
The capabilities of SAR for discriminating crop type have been previously explored (Boerner et al., 1987 and Haldar et al., 2012). Many studies have shown that SAR classifications were significantly improved based on a per-field approach due to the presence of speckle at the pixel level which was filtered out at the parcel level. Therefore, the greater the number of pixels that are averaged, i.e. the larger the field, the better the signal estimate. For example, a classification of seven different crop types based on ERS imagery using a field-based methodology was superior to the per-pixel approach (Tso and Mather, 1999).

Bouman and Kasteren (1990) reported that the geometrical architecture of the crop canopy was a major factor that influenced the $\mathrm{X}$ band radar backscattering of wheat, barley, oats, sugar beets and potatoes. Brisco and Brown (1990) showed that average backscattered was found to be higher for the healthier crops. Wooding et al. (1995) assumed that due to wind influences the plant geometry changes and thus the backscatter was influenced. They also reported that for small plants with thin stems as wheat, with vertical leaves dominating the backscatter, the impact is rather high.

\section{MATERIALS AND METHODS}

\subsection{Study area}

Perambalur district is a centrally located inland district of Tamil Nadu with a spread over of 1750 sq.kms. This district geographically lies from $10^{\circ} 53^{\prime}$ to $11^{\circ} 31^{\prime}$ North Latitudes and from $73^{\circ} 38^{\circ}$ to $79^{\circ} 31^{\circ}$ East Longitudes. This district has four blocks consisting of 152 revenue villages. The climate is hot sub humid to semi-arid. The mean annual maximum and minimum temperature are $32.6^{\circ} \mathrm{C}$ and $22.2^{\circ} \mathrm{C}$ respectively.

The area receives a mean annual rainfall of $908 \mathrm{~mm}$ out of which $475 \mathrm{~mm}$ is contributed by North East monsoon and 314 $\mathrm{mm}$ by South West monsoon. Black cotton soil, clay loam and red sandy soil are the predominant soil types. Maize, Cotton, Sorghum, Onion, Tapioca, Paddy, Groundnut and Sesamum are the major cultivated crops.

\subsection{Data used}

Sentinel1-A, carrying a C-band radar system with VV (Vertical-Vertical) and VH (Vertical-Horizontal) polarization obtained at twelve days interval was systematically used for crop inventory. Sentinel-1A has four standard operational modes, designed for interoperability with other system. Level-1 ground range (GRD) product obtained by interferometric wide (IW) swath mode (1) of High Resolution (HR) was used for this research. In order to have a full coverage during the crop growing period of Maize and Cotton, the satellite data were downloaded for $2^{\text {nd }}$ September 2017 to $24^{\text {th }}$ January 2018.

\subsection{Methodology}

Pre-processing was carried out using the tools available in the Sentinel1 toolbox of SNAP software. The VV and VH polarized intensity bands are processed for subsequent analysis. Multitemporal Sentinel1-A SAR is shown in Figure 1(a) and Figure 1(b) for VV and VH polarization, respectively. Subset creation, orbital correction, border noise removal and terrain correction process was applied on to the image (figure-2).
Multi-temporal data was then layer stacked, $\mathrm{VV}$ and $\mathrm{VH}$ polarization bands were subjected to multi-temporal speckle filtering using Gama-map with a window size of $3 \times 3$. The intensity values of SAR images were converted to decibel $(\mathrm{dB})$ using the linear to $\mathrm{dB}$ conversion tool and exported as geo-tiff for further processing.
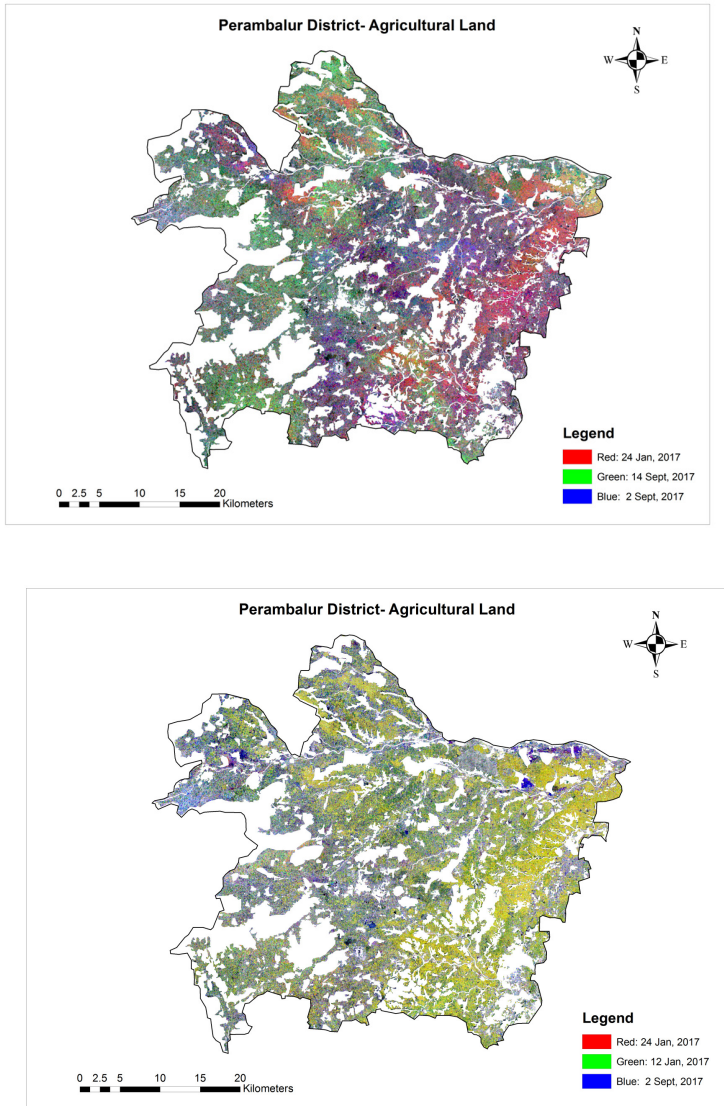

Figure 1: Multi-temporal Sentinel-1A data (a) VV polarization and (b) $\mathrm{VH}$ polarization

Subset creation, orbital correction, border noise removal and terrain correction process was applied on to the image (figure2). Multi-temporal data was then layer stacked, VV and $\mathrm{VH}$ polarization bands were subjected to multi-temporal speckle filtering using Gama-map with a window size of $3 \times 3$. The intensity values of SAR images were converted to decibel (dB) using the linear to $\mathrm{dB}$ conversion tool and exported as geo-tiff for further processing

Out of the collected ground truth information 60 per cent was used for training the classifiers and 40 per cent for accuracy assessment. Spectral Angle Mapper (SAM) and Decision Tree classifier (DT) methods were used in cotton and maize crop area classification. Spectral Angle Mapper (SAM) is a physically-based spectral classifier that uses an n-D angle to match pixels to reference spectra. SAM algorithm determines the spectral similarity between two spectra by calculating the angle between the spectra and treating them as vectors in a space with dimensionality equal to the number of bands. Decision tree is a non-parametric classifier and therefore it doesn't take into account the statistical distribution of the training data.

This Error matrix and Kappa statistics was used for evaluating the accuracy of the methods. The class allocation of each pixel 
in classified image was compared with the corresponding class allocation on reference data to determine the classification accuracy.

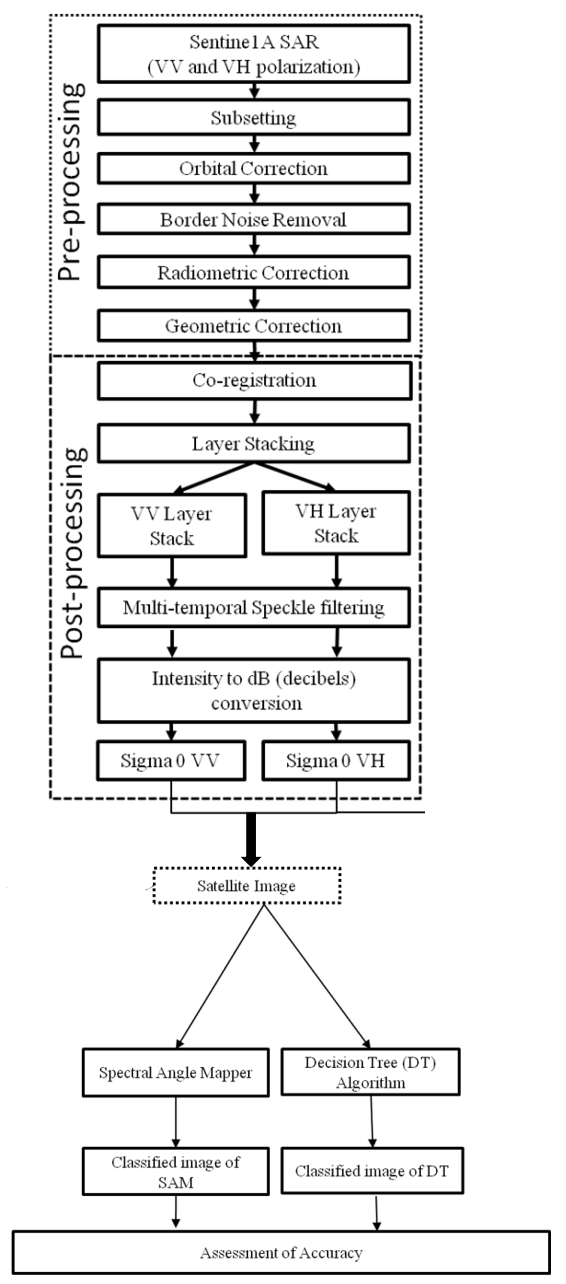

Figure 2: Methodology for classification for multi-temporal SAR data

\section{RESULTS AND DISCUSSION}

The SAR data collected during the cropping period were processed and analysed using the training pixels to derive the temporal backscattering coefficient $(\sigma 0)$ for Cotton and Maize. The mean temporal backscattering signature for VerticalVertical (VV) and Vertical-Horizontal (VH) polarized SAR data for cotton and maize are provided in Tables 1 and 2 .

The backscatter values for cotton crop during the entire cropping period ranges from $-11.729 \mathrm{~dB}$ to $-8.827 \mathrm{~dB}$ and from $-19.167 \mathrm{~dB}$ to $-14.186 \mathrm{~dB}$ for $\mathrm{VV}$ and $\mathrm{VH}$ polarization, respectively. For maize crop it ranged from $-11.248 \mathrm{~dB}$ to $8.878 \mathrm{~dB}$ and from $-19.043 \mathrm{~dB}$ to $-14.753 \mathrm{~dB}$ for $\mathrm{VV}$ and $\mathrm{VH}$ polarization, respectively. It was observed that maize and cotton crop backscatter values increased with progression of crop in both VV and $\mathrm{VH}$ polarization, the mean backscatter of $\mathrm{VV}$ polarization showed that the $\mathrm{dB}$ difference between maize and cotton increases from November onwards to greater than $1 \mathrm{~dB}$ and similar $\mathrm{dB}$ difference in $\mathrm{VH}$ backscatter was also observed from December month onwards. VV polarization showed more sensitivity to these changes and this in line with work reported by Aubert et al. (2011).
Image classification was carried out on the temporal backscatter image. Spectral Angle Mapper and Decision tree classifiers were used in this study for extracting information from multitemporal SAR data. Classification was performed using multitemporal VV data.

\begin{tabular}{|c|c|c|}
\hline \multirow{2}{*}{$\begin{array}{c}\text { Date of Satellite } \\
\text { pass }\end{array}$} & \multicolumn{2}{|c|}{ VV Polarization } \\
\cline { 2 - 3 } & Cotton (dB) & Maize (dB) \\
\hline $02 / 09 / 2017$ & -11.729 & -11.248 \\
\hline $14 / 09 / 2017$ & -10.047 & -10.767 \\
\hline $26 / 09 / 2017$ & -8.497 & -9.298 \\
\hline $08 / 10 / 2017$ & -8.429 & -9.578 \\
\hline $20 / 10 / 2017$ & -8.174 & -8.958 \\
\hline $01 / 11 / 2017$ & -7.712 & -8.964 \\
\hline $13 / 11 / 2017$ & -7.991 & -9.729 \\
\hline $25 / 11 / 2017$ & -7.290 & -8.827 \\
\hline $07 / 12 / 2017$ & -7.823 & -9.024 \\
\hline $19 / 12 / 2017$ & -8.352 & -9.881 \\
\hline $31 / 12 / 2017$ & -8.532 & -10.505 \\
\hline $12 / 01 / 2018$ & -8.502 & -9.646 \\
\hline $24 / 01 / 2018$ & -9.095 & -11.155 \\
\hline
\end{tabular}

Table-1: Temporal backscatter signature for maize and cotton using VV Polarization from Sentinel-1A

\begin{tabular}{|c|c|c|}
\hline \multirow{2}{*}{$\begin{array}{c}\text { Date of Satellite } \\
\text { pass }\end{array}$} & \multicolumn{2}{|c|}{ VH Polarization } \\
\cline { 2 - 3 } & Cotton (dB) & Maize (dB) \\
\hline $02 / 09 / 2017$ & -19.167 & -19.043 \\
\hline $14 / 09 / 2017$ & -18.007 & -18.536 \\
\hline $26 / 09 / 2017$ & -15.110 & -15.657 \\
\hline $08 / 10 / 2017$ & -15.534 & -15.394 \\
\hline $20 / 10 / 2017$ & -15.157 & -15.258 \\
\hline $01 / 11 / 2017$ & -14.873 & -14.766 \\
\hline $13 / 11 / 2017$ & -15.141 & -15.768 \\
\hline $25 / 11 / 2017$ & -14.434 & -14.753 \\
\hline $07 / 12 / 2017$ & -14.186 & -15.067 \\
\hline $19 / 12 / 2017$ & -14.560 & -15.584 \\
\hline $31 / 12 / 2017$ & -15.043 & -16.505 \\
\hline $12 / 01 / 2018$ & -14.480 & -15.554 \\
\hline $24 / 01 / 2018$ & -15.313 & -16.913 \\
\hline
\end{tabular}

Table-2: Temporal backscatter signature for maize and cotton using VH Polarization from Sentinel-1A

Two crops viz., cotton and maize were classified. As compared to the crop area statistics from state department of agriculture of 43250 hectares for cotton and 33400 ha, a total area of 73259 and 51489 ha, as cotton and maize, respectively was classified using SAM and DT classifier, classified a total area of 61501 and 64530 ha as cotton and maize, respectively (Figure 3). Accuracy assessment was conducted on the per pixel basis randomly spread over the study area. The overall accuracy, was found to be at 73.30 per cent for SAM \& 76 per cent for DT 
classifier. Kappa coefficient was 0.47 for SAM \& 0.50 for DT classifier.

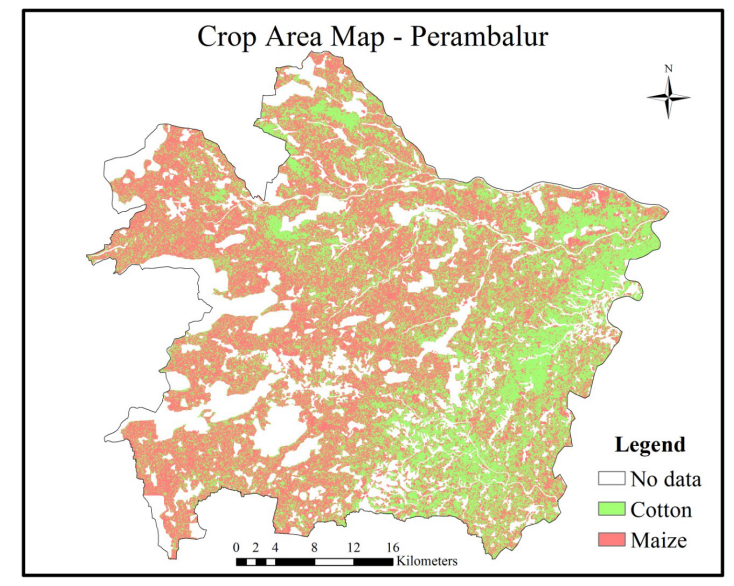

Figure 3: Crop area map as classified using Decision tree classifier

It can be inferred that the backscattering value for cotton and maize has good separability during the maturity stage and it is in line with the results reported by the authors Forkuor et al., (2014) and Liang and Chunyu (2009).

\section{CONCLUSION}

In the present study, the potential of multi-temporal Sentinel1A SAR sensor for mapping cotton and maize area were examined using $\mathrm{VV}$ and $\mathrm{VH}$ polarization. The mean backscattering values of cotton and maize at the peak crop growth stage $\left(\sigma_{\mathrm{D} 4}^{0}\right.$ to $\left.\sigma_{\mathrm{D} 9}^{0}\right)$ showed an increase in backscatter value of $1.0 \mathrm{~dB}$ to $2 \mathrm{~dB}$ than the initial establishment $\left(\sigma_{\mathrm{D} 3}^{0}\right)$. It is evident from the present study, that the multi-temporal Sentinel 1-A SAR sensor can be well used for the discrimination of cotton and maize crops because of its high temporal resolution which captures the complete phenology of the crops during the cropping period. Rainfall during the image acquisition period can introduce misleading backscatter values, so such data sets can be removed and rule based classification can be used to improve the classification. Additionally polarimetric parameters can be evaluated also to improve accuracy in crop classification.

\section{REFERENCES}

Aubert, M., N. Baghdadi, M. Zribi, A. Douaoui, C. Loumagne, F. Baup, M. El Hajj and S. Garrigues. 2011. Analysis of TerraSAR-X data sensitivity to bare soil moisture, roughness, composition and soil crust. Remote Sensing Environment, 115, pp. 1801-1810.

Boerner, W.M., B.Y. Foo and H.J. Eom. 1987. Interpretation of the polarimetric co-polarization phase term in radar images obtained with JPL airborne L-band SAR system. IEEE Transactions on Geoscience \& Remote Sensing, 25(1), pp.7782.

Bouman, B. and H. Van Kasteren. 1990. Ground-based x-band ( $3 \mathrm{~cm}$ wave) radar backscattering of agricultural crops. ii: Wheat, barley and oats; the impact of canopy structure. Remote Sensing Environment, 34(2), pp. 107-118.
Brisco, B. and R.J. Brown. 1990. Drought Stress Evaluation in Agricultural Crops Using C-HH SAR Data. Canadian Journal of Remote Sensing, 16 (3), pp. 39-47.

Brisco, B., R.J. Brown, T. Hirose, H. McNairn and K. Staenz. 1998. Precision agriculture and the role of remote sensing: A Review. Canadian Journal of Remote Sensing, 24(3), pp. 315327

Dadhwal, V.K., R.P. Singh, S. Dutta and J.S. Parihar. 2000. Remote Sensing based crop inventory: A review of Indian express. International Society for Tropical Ecology, 43(1), pp. 107-122.

Fisette, T., Maloley, M. Chenier, R. White, L. Huffman, T. Ogston, R. Pacheco and P.Y. Gasser. 2005. Towards a national agricultural land cover classification-evaluating decision tree approach. In: Proceedings of the 26th Canadian Symposium on Remote Sensing, Wolfville, NS, Canada, pp. 385-389.

Forkuor, G. and O. Cofie. 2011. Dynamics of land-use and land-cover change in Freetown, Sierra Leone and its effects on urban and peri-urban agriculture-A remote sensing approach. International Journal of Remote Sensing, 32, pp. 1017-1037.

Haldar, D., A. Das, S. Mohan, O. Pal, R.S. Hooda and M. Chakraborty. 2012. Assessment of L-band SAR data at different polarization combinations for crop and other land use classification. Progressed in Electromagnetic Research $B$. (PIER), 36, pp. 303-321.

Liang, P. and Y. Chunyu. 2009. Study on mixed pixel classification method of remote sensing image based on fuzzy theory. Urban Remote Sensing Joint Event, pp. 1-7.

McNairn, David Lapen, Mark Sunohara and Catherine Champagne. 2014. Assessment of RapidEye vegetation indices for estimation of leaf area index and biomass in corn and soybean crops. International Journal of Applied Earth Observation and Geoinformation, 24, pp. 235-248.

Schuster, C., I. Ali, P. Lohmann, A. Frick, M. Foerster and B. Kleinschmit. 2011. Towards detecting swath events in TerraSAR-X time series to establish NATURA 2000 grassland habitat swath management as monitoring parameter. Remote Sensing Environment, 3, pp. 1308-1322.

Shang, J., H. McNairn, C. Champagne and X. Jiao. 2009. Contribution of multi-frequency, multi-sensor, and multitemporal radar data to operational annual crop mapping. IEEE Transactions on Geoscience and Remote Sensing, 3(1), pp. III378-III381.

Susan Moran, M., Luis Alonso, Jose, F. Moreno, Maria Pilar Cendrero Mateo, D. Fernando de la Cruz and Amelia Montoro. 2011. A RADARSAT-2 Quad-Polarized Time Series for Monitoring Crop \& Soil Conditions in Barrax, Spain. IEEE Transactions on Geosciences \& Remote Sensing, 12(3), pp.1-14

Tso, B. and P.M. Mather. 1999. Crop discrimination using multi-temporal SAR imagery. International Journal of Remote Sensing, 20, pp. 2443-2460.

Wooding, M., E. Attema, J. Aschbacher, M. Borgeaud, R. Cordey, H. De Groof, J. Harms, J. Lichtenegger, G. Nieuwenhuis, C. Schmullius and A. Zmuda. 1995. Satellite 
The International Archives of the Photogrammetry, Remote Sensing and Spatial Information Sciences, Volume XLII-3/W6, 2019 ISPRS-GEOGLAM-ISRS Joint Int. Workshop on "Earth Observations for Agricultural Monitoring”, 18-20 February 2019, New Delhi, India

radar in agriculture. Experience with ers-1. Technical report, ESA SP-1185, ISBN 90-9092- 339. 